\title{
Glutamate Transport Decreases Mitochondrial pH and Modulates Oxidative Metabolism in Astrocytes
}

\author{
Guillaume Azarias, ${ }^{1}$ Hélène Perreten, ${ }^{3}$ Sylvain Lengacher, ${ }^{3}$ Damon Poburko, ${ }^{4}$ Nicolas Demaurex, ${ }^{4}$ \\ Pierre J. Magistretti, ${ }^{3,5}$ and Jean-Yves Chatton ${ }^{1,2}$ \\ ${ }^{1}$ Department of Cell Biology and Morphology and ${ }^{2}$ Cellular Imaging Facility, University of Lausanne, CH-1005 Lausanne, Switzerland, ${ }^{3}$ Laboratory of \\ Neuroenergetics and Cellular Dynamics, Brain and Mind Institute, Ecole Polytechnique Fédérale de Lausanne, CH-1015 Lausanne, Switzerland, \\ ${ }^{4}$ Department of Cell Physiology and Metabolism, University of Geneva, CH-1211 Geneva, Switzerland, and ${ }^{5}$ Center for Psychiatric Neuroscience Lausanne, \\ CH-1008 Lausanne, Switzerland
}

During synaptic activity, the clearance of neuronally released glutamate leads to an intracellular sodium concentration increase in astrocytes that is associated with significant metabolic cost. The proximity of mitochondria at glutamate uptake sites in astrocytes raises the question of the ability of mitochondria to respond to these energy demands. We used dynamic fluorescence imaging to investigate the impact of glutamatergic transmission on mitochondria in intact astrocytes. Neuronal release of glutamate induced an intracellular acidification in astrocytes, via glutamate transporters, that spread over the mitochondrial matrix. The glutamate-induced mitochondrial matrix acidification exceeded cytosolic acidification and abrogated cytosol-to-mitochondrial matrix pH gradient. By decoupling glutamate uptake from cellular acidification, we found that glutamate induced a pH-mediated decrease in mitochondrial metabolism that surpasses the $\mathrm{Ca}^{2+}$-mediated stimulatory effects. These findings suggest a model in which excitatory neurotransmission dynamically regulates astrocyte energy metabolism by limiting the contribution of mitochondria to the metabolic response, thereby increasing the local oxygen availability and preventing excessive mitochondrial reactive oxygen species production.

\section{Introduction}

Recent advances in neuroenergetics tend to indicate that the major energetic cost in brain cortex takes place at glutamatergic synapses (Sibson et al., 1998; Alle et al., 2009) and involves a tight metabolic coupling between neurons and perisynaptic astroglial processes surrounding glutamatergic synapses (Chatton et al., 2003; Voutsinos-Porche et al., 2003; Magistretti, 2009). It has been proposed that the activity of glutamate transporters expressed at the plasma membrane of astrocytes is associated with an intracellular $\mathrm{Na}^{+}$increase correlated with the mobilization of the plasma membrane Na, K-ATPase activity, and an ensuing substantial increase in ATP consumption (Magistretti et al., 1999). Consistently, it has been shown that glutamatergic synaptic activity triggers an energetic demand in astrocytes that generates a diffusion gradient for glucose within a network of astrocytes, directly linked to the level of neuronal activity (Rouach et al., 2008). The nature and regulation of the glucose metabolism within astrocytes are of crucial importance for the interpretation of functional neuroimaging signals and remain a debated issue.

\footnotetext{
Received Aug. 20, 2010; revised Dec. 3, 2010; accepted Jan. 3, 2011.

This work was supported by Swiss National Science Foundation Grant 3100A0-119827 (J.-Y.C.). We thank Steeve Menétrey for his technical assistance, Véronique Perret and Romano Regazzi for help with constructs for transfection, Luigi Bozzo for neuronal cultures, Rosario Rizzuto (University of Ferrara, Ferrara, Italy) and Anna Maria Porcelli (University of Bologna, Bologna, Italy) for providing the MIMS-EYFP construct, and Rudolf Kraftsik for his help with the statistical analysis.

Correspondence should be addressed to Jean-Yves Chatton, Department of Cell Biology and Morphology, University of Lausanne, Rue du Bugnon 9, CH-1005 Lausanne, Switzerland. E-mail: jean-yves.chatton@unil.ch.

DOI:10.1523/JNEUROSCI.4378-10.2011

Copyright $\odot 2011$ the authors $\quad 0270-6474 / 11 / 313550-10 \$ 15.00 / 0$
}

In vitro experiments showed that glutamate uptake enhances lactate release, suggesting that glycolysis is the dominant pathway involved (Pellerin and Magistretti, 1994). However, the contribution of mitochondria to the metabolic response remains elusive (Pellerin and Magistretti, 2003), although direct and indirect evidence suggests a certain degree of oxidative activity in astrocytes (Lovatt et al., 2007; Wyss et al., 2009) and astrocytes also experience activity-dependent increases in cytosolic $\mathrm{Ca}^{2+}$ (Schummers et al., 2008).

Ultrastructural analysis of astrocyte-neuron tripartite synapses have indicated that fine astrocytic processes ensheathing synapses contain a substantial density of mitochondria (Grosche et al., 1999; Lovatt et al., 2007; Oberheim et al., 2009). Accordingly, it was estimated that astrocytes account for $\sim 25 \%$ of total brain oxidative metabolism as measured by nuclear magnetic resonance spectroscopy (Serres et al., 2008). The presence of mitochondria in the immediate vicinity of plasmalemmal glutamate transporters in astrocytes (Chaudhry et al., 1995; Haugeto et al., 1996; Bezzi et al., 2004) raises the question of whether factors such as ion concentration changes associated with glutamate uptake have an impact on mitochondrial metabolism.

To address this issue, we used cultured cortical astrocytes as a model of perisynaptic astroglial process. The thin morphology of astrocytes in culture enables studying mitochondria in the proximity of plasma membrane glutamate transporters and in an intact cellular environment. We used real-time fluorescence imaging to follow intracellular ionic alterations during glutamate superfusion and studied the impact of glutamate on the metabolism of astrocyte mitochondria in situ. In previous studies, we 
have shown that the mitochondrial $\mathrm{Na}^{+}$concentration increases as a result of glutamate transporter activity (Bernardinelli et al., 2006). In the present study, using a fluorescent $\mathrm{pH}$ biosensor targeted to the mitochondrial matrix, we show that glutamate, released from neurons or applied by superfusion, induces a dosedependent proton transfer into mitochondria that depends on glutamate transporter activity. We further show that this proton transfer weakens the cytosol-to-mitochondrial matrix $\mathrm{pH}$ gradient and induces the sustained decrease in mitochondrial oxidative metabolism that dominates the $\mathrm{Ca}^{2+}$-mediated stimulatory effect of glutamate.

\section{Materials and Methods}

\section{Cell culture and solutions}

Cortical astrocytes in primary culture were prepared from 1- to 3-d-old from C57BL/6 mice as described previously (Sorg and Magistretti, 1992). Astrocytes were plated on $20 \mathrm{~mm}$ glass coverslips and cultured for 2-4 weeks in DMEM (Sigma) plus 10\% FCS. Cocultures of neurons and astrocytes were prepared from 2-week-old primary cultures of astrocytes transfected with MitoSypHer (see below) on which neurons prepared from cerebral cortex of embryonic day 17 mice (C57BL/6) were plated. Briefly, neurons were prepared as follows. Cortex were dissected and incubated with $200 \mathrm{U}$ of papain for $30 \mathrm{~min}$ at $34^{\circ} \mathrm{C}$. Dissociated cells were plated at $0.8 \times 10^{6}$ cells per dish. Cocultures of cortical neurons were grown in B27/Neurobasal (Invitrogen) supplemented with $0.5 \mathrm{mmol} / \mathrm{L}$ glutamine and $100 \mu \mathrm{g} / \mathrm{ml}$ penicillin-streptomycin for $14 \mathrm{~d}$.

Experimental solutions contained the following (in $\mathrm{mm}$ ): $160 \mathrm{NaCl}$, $5.4 \mathrm{KCl}, 20 \mathrm{HEPES}, 1.3 \mathrm{CaCl}_{2}, 0.8 \mathrm{MgSO}_{4}, 0.78 \mathrm{NaH}_{2} \mathrm{PO}_{4}$, and 5 glucose, $\mathrm{pH} 7.4$, bubbled with air. Solutions for dye loading contained the following (in mM): $160 \mathrm{NaCl}, 5.4 \mathrm{KCl}, 20$ HEPES, $1.3 \mathrm{CaCl}_{2}, 0.8 \mathrm{MgSO}_{4}, 0.78$ $\mathrm{NaH}_{2} \mathrm{PO}_{4}$, and 20 glucose (supplemented with $0.1 \%$ Pluronic F127; Invitrogen). Calibration solutions for mitochondrial matrix $\mathrm{pH}$ contained the following (in mM): $20 \mathrm{NaCl}, 125 \mathrm{KCl}, 0.5 \mathrm{MgCl}_{2}, 0.2 \mathrm{EGTA}$, and 20 HEPES, bubbled with air. Calibration solutions for mitochondrial intermembrane space $\mathrm{pH}$ contained the following (in $\mathrm{mM}$ ): $10 \mathrm{NaCl}, 125 \mathrm{KCl}$, $1 \mathrm{CaCl}_{2}, 1 \mathrm{MgSO}_{4}, 1 \mathrm{KH}_{2} \mathrm{PO}_{4}$, and 20 HEPES.

\section{Astrocyte transfection}

Two-week-old astrocytes were placed in $2 \mathrm{ml}$ of antibiotic-free and serum-free DMEM with Fugene (Roche) and DNA encoding for MitoSypHer or MIMS-EYFP (enhanced yellow fluorescent protein targeted to the mitochondrial intermembrane space). Quantities of microgram of DNA per microliters of FuGene were 2/12 and 4/8 for MitoSypHer and MIMS-EYFP, respectively. After $4 \mathrm{~h}$, the medium was changed with DMEM plus $10 \%$ serum, and cells were used 2-3 d after transfection for pure astrocyte culture and $14 \mathrm{~d}$ for mixed neuron-astrocyte cultures.

\section{Live cell imaging}

Epifluorescence microscopy. Low-light level fluorescence imaging was performed on an inverted epifluorescence microscope (Axiovert 100M; Carl Zeiss) using a $40 \times, 1.3$ numerical aperture oil-immersion objective lens. Fluorescence excitation wavelengths were selected using a monochromator (T.I.L.L. Photonics), and fluorescence was detected using a 12-bit cooled CCD camera (Princeton Instruments). Image acquisition and time series were computer controlled using the software Metafluor (Molecular Devices) running on a Pentium computer.

Cells were loaded in a HEPES-buffered balanced solution and then placed in a thermostated chamber designed for rapid exchange of perfusion solutions (Chatton et al., 2000) and superfused at $35^{\circ} \mathrm{C}$. To avoid phototoxicity, excitation intensity was reduced to $\sim 10 \mu \mathrm{W}$ (as measured at the entrance pupil of the objective) by means of neutral density filters.

For mitochondrial matrix $\mathrm{pH}$ measurement, we used the genetically encoded pH indicator MitoSypHer (Poburko et al., 2011). The probe enables ratiometric measurements that correct for changes in focal plane, organelle swelling, and photobleaching. It therefore faithfully reflects the $\mathrm{pH}$ changes that occur within mitochondria in living cells. MitoSypHer fluorescence was sequentially excited at 490 and $420 \mathrm{~nm}$ and detected at $>515 \mathrm{~nm}$. At the end of each experiment, in situ calibration was per- formed as described in supplemental Figure S1 (available at www. jneurosci.org as supplemental material). Mitochondrial intermembrane space was investigated as reported previously (Porcelli et al., 2005). Intracellular $\mathrm{pH}$ measurement was performed using the $\mathrm{pH}$-sensitive dye 2-bis(carboxyethyl)-5,6-carboxyfluorescein (BCECF)-AM and $\mathrm{Ca}^{2+}$ with fura-2 AM as described previously (Chatton et al., 2001).

Cytosolic $\mathrm{Na}^{+}$was measured as described previously (Chatton et al., 2000) using the indicator sodium-binding benzofuran isophthalate (SBFI-AM) (Teflabs). Cell loading was performed at $37^{\circ} \mathrm{C}$ using $15 \mu \mathrm{M}$ SBFI-AM, and fluorescence was sequentially excited at 340 and $380 \mathrm{~nm}$ and detected at $>520 \mathrm{~nm}$. Fluorescence excitation ratios $\left(F_{340 \mathrm{~nm}} / F_{380 \mathrm{~nm}}\right)$ were computed for each image pixel and calibrated to yield actual $\mathrm{Na}^{+}{ }_{\mathrm{i}}$ concentrations as described in detail previously (Chatton et al., 2000). Mitochondrial $\mathrm{Na}^{+}$concentration was investigated and calibrated as described by Bernardinelli et al. (2006) using the indicator CoroNa Red that specifically loads in mitochondria. CoroNa Red fluorescence was excited at $570 \mathrm{~nm}$ and detected at $>590 \mathrm{~nm}$.

Mitochondrial reactive oxygen species (mROS) production rate was measured using the mitochondrially targeted dye MitoSOX Red (Robinson et al., 2006). MitoSOX Red was loaded at $0.5 \mu \mathrm{M}$ for $20 \mathrm{~min}$ at $37^{\circ} \mathrm{C}$. Its fluorescence was excited at $510 \mathrm{~nm}$ and collected above $580 \mathrm{~nm}$. For each experimental condition, the MitoSOX Red fluorescence slope was calculated using the software Kaleidagraph (Synergy Software) by performing the first-order derivative of locally weighted least-square error fit of the original traces. Data are reported as percentage of the slope measured in 2-deoxyglucose (2-DG) medium containing pyruvate. As a control, antimycin A $(20 \mu \mathrm{g} / \mathrm{ml})$ was applied to verify MitoSOX Red sensitivity to mROS level.

Confocal microscopy. To verify the mitochondrial localization of the MitoSypHer and MIMS-EYFP proteins, transfected astrocytes were loaded for $20 \mathrm{~min}$ with MitoTracker Red ( $1 \mu \mathrm{M}$; Invitrogen) at $37^{\circ} \mathrm{C}$ and imaged by confocal microscopy (LSM 510 Meta; Carl Zeiss) using excitation light at 488 and $543 \mathrm{~nm}$. Fluorescence emissions were collected at 505-530 nm (MitoSypHer or MIMS-EYFP) and >560 nm (MitoTracker Red).

Simultaneous monitoring of cytosolic and mitochondrial $\mathrm{pH}$ was performed at $37^{\circ} \mathrm{C}$ on a TCS SP 5 confocal microscope using its $8 \mathrm{kHz}$ Tandem resonant scanner (Leica Microsystems). The pH-sensitive cytosolic red dye SNARF-1 (carboxylseminaphthorhodafluo-1) (AM) was loaded for 25-30 min in HEPES loading solution and then washed for $15 \mathrm{~min}$ in HEPES solution containing glucose. Mitochondrial and cytosolic $\mathrm{pH}-$ sensitive indicators were excited using $488 \mathrm{~nm}$ low-intensity laser light illumination, and fluorescence was collected in three separated channels. MitoSypHer fluorescence emission was collected in the range 500-530 $\mathrm{nm}$, and the emission ratio $(620 \mathrm{~nm}-765 \mathrm{~nm}) /(560 \mathrm{~nm}-600 \mathrm{~nm})$ was used for SNARF-1. At the end of each experiment, mitochondrial and cytosolic $\mathrm{pH}$ were simultaneously calibrated as described previously (Poburko et al., 2011).

\section{Oxygen consumption rate}

The oxygen consumption rate was assessed using an Extracellular Flux Analyzer (Seahorse Biosciences). Extracellular flux analysis is a noninvasive assay that uses calibrated optical sensors that directly measures the oxygen consumption rate in cells that remain attached to the culture plate. Before experiments, astrocytes were incubated $1 \mathrm{~h}$ at $37^{\circ} \mathrm{C}$ in a $\mathrm{CO}_{2}$-free incubator in a $10 \mathrm{~mm}$ HEPES-buffered DMEM containing $10 \mathrm{~mm} 2-\mathrm{DG}, 5 \mathrm{~mm}$ glucose, and $5 \mathrm{~mm}$ pyruvate. Glutamate and triethylammonium (TREA) were injected in the medium at final concentrations of $200 \mu \mathrm{M}$ and $20 \mathrm{mM}$, respectively. Oligomycin $(5 \mu \mathrm{M})$ and carbonyl cyanide $p$-trifluoromethoxyphenylhydrazone (FCCP) $(2 \mu \mathrm{M})$ were used as controls to inhibit and maximize mitochondrial respiration, respectively.

\section{Statistics}

Unless otherwise indicated, a paired Student's $t$ test was performed for each experiment group to assess the statistical significance against respective controls, ${ }^{*},{ }^{* *}$, and ${ }^{* *}$ refer to $p$ values $<0.05,0.01$, and 0.001 , respectively. For the analysis of distributions of mitochondrial matrix and cytosolic $\mathrm{pH}, p$ value was calculated using the two-tailed ANOVA on exponentially transformed $\mathrm{pH}$ values (SAS Institute). 


\section{Materials}

All chemical dyes were from Invitrogen. Glutamate, D-aspartate, kainate, CNQX, and DL-threo$\beta$-benzyloxyaspartate (TBOA) were from Tocris Bioscience (ANAWA Trading). Neurobasal was from Invitrogen. Ethyl-isopropyl amiloride (EIPA) was a gift from Dr. H. Lang (Aventis Pharma, Frankfurt, Germany). Manganese (III) tetrakis(1-methyl-4-pyridyl)porphyrin (MnT$\mathrm{MPyP}$ ) was from Calbiochem. All other substances were from Sigma.

\section{Results}

Glutamate induces mitochondrial $\mathrm{pH}$ changes in astrocytes

Glutamate uptake was shown to decrease cytosolic pH in cultured astrocytes (Rose and Ransom, 1996) and in hippocampal slices (Amato et al., 1994), but the impact of cytosolic acidification on mitochondrial physiology is not known. To address this issue, we used the genetically encoded $\mathrm{pH}$-sensitive fluorescent biosensor MitoSypHer targeted to the mitochondrial matrix (Poburko et al., 2011). Two-week-old cultured astrocytes transfected with MitoSypHer plasmid exhibited a fluorescent protein expression pattern typical of mitochondrial labeling, with dark nuclei and punctate staining of rod-like structures (Fig. $1 a_{1}$ ). In living cells, the expression of MitoSypHer perfectly matched the MitoTracker Red mitochondrial staining (Fig. $\left.1 a_{2}, a_{3}\right)$. In situ calibration of MitoSypHer signal, performed as depicted in supplemental Figure S1 (available at www. jneurosci.org as supplemental material), indicates that fluorescence excitation ratio was correlated with $\mathrm{pH}$ (Fig. $1 b_{1}$ ).

According to the chemioosmotic coupling hypothesis, mitochondrial matrix is expected to be more alkaline than cytosol because of the anticipated low permeability of the mitochondrial inner membrane and the constant extrusion of protons across mitochondrial inner membrane by the mitochondrial respiratory chain (Mitchell, 1979). Consistently, the resting mitochondrial matrix $\mathrm{pH}$ was found to be significantly higher than that of the cytosol measured in separate experiments using the indicator BCECF-AM (supplemental Fig. S5, available at www.jneurosci.org as supplemental material) or simultaneously using SNARF-1 (see Fig. 3). However, glutamate superfusion of astrocytes caused a rapid and significant drop in mitochondrial matrix $\mathrm{pH}$ (Fig. 1 $b_{2}$ ) whose amplitude was even greater than that found in the cytosol (Fig. 1c).

Glutamate superfusion $(200 \mu \mathrm{M})$ also induced a rapid and significant $\mathrm{pH}$ drop in the mitochondrial intermembrane space (supplemental Fig. S2, available at www.jneurosci.org as supplemental material) measured using the MIMS-EYFP biosensor (Porcelli et al., 2005). The intermembrane space displayed an acidification of equal amplitude compared with the glutamateinduced cytosolic acidification (Fig. 1c), which is consistent with the described high permeability of the outer mitochondrial membrane to ions and small solutes attributable to the presence of mitochondrial porins (Blachly-Dyson and Forte, 2001). Thus, we
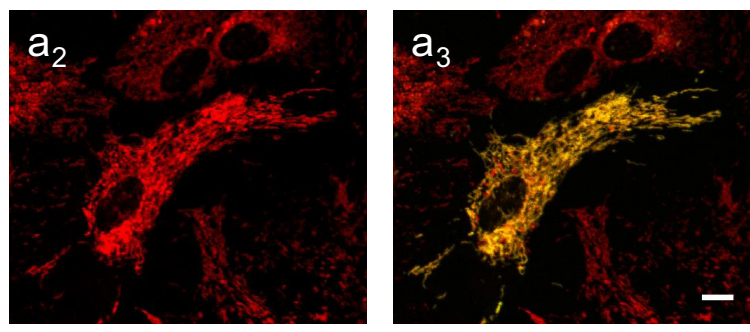

$\mathrm{b}_{2}$

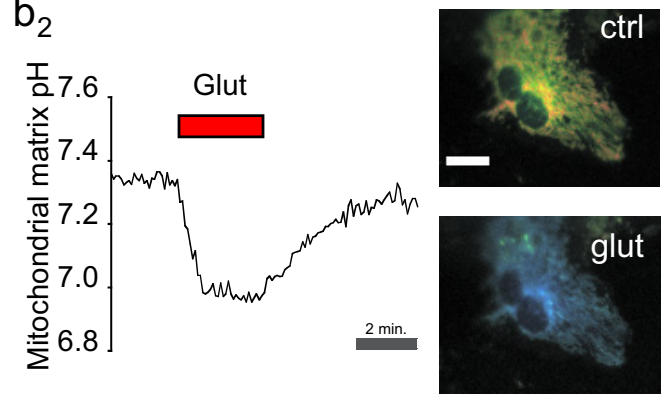
$\mathrm{pH}$

d

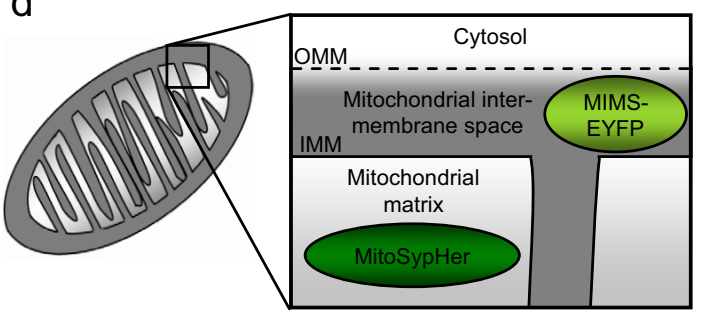

Figure 1. Glutamate evokes mitochondrial acidification in astrocytes. $\boldsymbol{a}$, Images of cortical astrocytes expressing MitoSypHer ypHer fluorescence excitation ratio versus $\mathrm{pH} . \boldsymbol{b}_{2}$, Glutamate $(200 \mu \mathrm{m})$ superfusion on intact astrocytes acidified the mitochon( acidifications induced by glutamate in the cytosol ( $n=23,172$ cells), MIMS ( $n=9,26$ cells), and mitochondrial matrix ( $n=46$ 168 cells). Data are shown as means \pm SEM. $\boldsymbol{d}$, Scheme for the localization of mitochondrial pH sensors (MIMS-EYFP and MitoSypHer). IMM, Inner mitochondrial membrane; OMM, outer mitochondrial membrane.

focused the rest of the study on the mitochondrial matrix compartment.

\section{Glutamate-evoked mitochondrial matrix $\mathrm{pH}$ acidification is mediated by glutamate transporters}

The observed kinetics of acidification (Fig. $1 b_{2}$ ) was reminiscent of a transporter-mediated process. Therefore, we investigated the concentration dependence parameters of glutamate-evoked mitochondrial matrix acidification. Both the amplitude and initial rate of glutamate-induced mitochondrial matrix acidification followed a Michaelis and Menten relationship with glutamate concentration (Fig. 2a). The maximal amplitude of mitochondrial matrix acidification was observed at $200 \mu \mathrm{M}$ glutamate, and the apparent $\mathrm{EC}_{50}$ was $13.2 \pm 5.1 \mu \mathrm{M}$. The initial rate of mitochondrial matrix acidification yielded an $\mathrm{EC}_{50}$ value of $83 \pm 25 \mu \mathrm{M}$. Because kinetic parameters of glutamate-induced mitochondrial acidification closely matched values found previously for $\mathrm{Na}^{+}$-dependent plasma-membrane glutamate transport (Chatton et al., 2000), we attempted to inhibit glutamate transport using TBOA, a competitive inhibitor of glutamate transporters with a broad isoform selectivity. Indeed, TBOA $(500 \mu \mathrm{M})$ reversibly inhibited the glutamate-evoked 


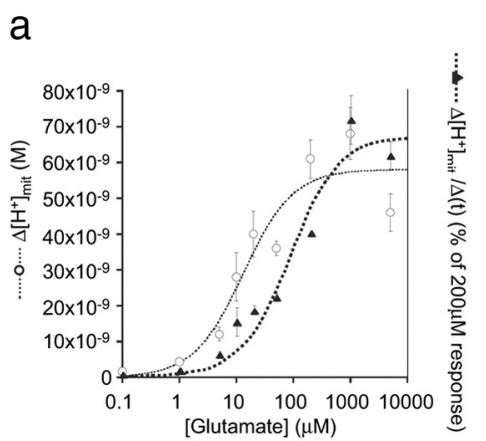

b

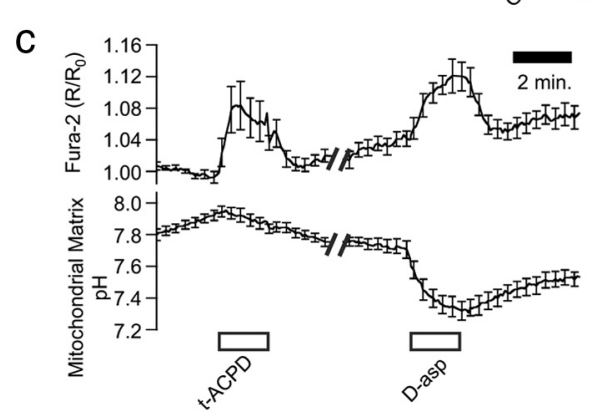

Figure 2. Glutamate evokes a concentration-dependent mitochondrial matrix acidification mediated by glutamate transporters. $\boldsymbol{a}$, Concentration dependence of the amplitude (open circles) and initial slope (filled triangles) of glutamate-induced mitochondrial matrix acidification ( $n=24,80$ cells). $\boldsymbol{b}$, TBOA reversibly inhibited a $200 \mu \mathrm{m}$ glutamate-evoked mitochondrial matrix acidification. Amplitude of glutamate-induced mitochondrial matrix acidification before during and after TBOA ( $n=5,30$ cells). See also supplemental Figure S2 (available at www.jneurosci.org as supplemental material). c, $\mathrm{Ca}^{2+}$ (top curves) and $\mathrm{pH}_{\text {mit }}$ (bottom curves) responses were simultaneously monitored using fura-2 in MitoSypHer-transfected astrocytes. The applications of the mGluR agonist ( $t$-ACPD, 100 $\mu \mathrm{m})$ and glutamate transporter substrate D-asp (200 $\mu \mathrm{m})$ are indicated in the graph. Traces are shown as mean signals with error bars (SEM) displayed every third time point for graphical clarity ( $n=5,8$ cells).

mitochondrial matrix acidification by $75 \pm 2 \%$ (Fig. $2 b$ ) (supplemental Fig. S3, available at www.jneurosci.org as supplemental material). In addition, mitochondrial matrix $\mathrm{pH}$ was measured in cells that do not express glutamate transporters, namely HEK-293 cells. We found that glutamate application did not alter mitochondrial matrix $\mathrm{pH}$ in these cells (supplemental Fig. S4, available at www.jneurosci.org as supplemental material). Astrocytic cytosolic $\mathrm{Ca}^{2+}$ is expected to increase in the presence of glutamate after activation of metabotropic receptors (mGluRs) and plasma membrane $\mathrm{Na}^{+} / \mathrm{Ca}^{2+}$ antiporter activity. The $\mathrm{Ca}^{2+}$ increase itself was shown to lead to mitochondrial acidification in HeLa cells by means of plasma membrane $\mathrm{Ca}^{2+} / \mathrm{H}^{+}$exchange mediated by the Ca-ATPase (Poburko et al., 2011). To test whether this mechanism was also involved in astrocytes, we simultaneously monitored the mitochondrial matrix $\mathrm{pH}$ and cytosolic $\mathrm{Ca}^{2+}$ during application of ( \pm )-1-amino-1,3-cyclopentanedicarboxylic acid (t-ACPD), a nonselective mGluR agonist that is not transported, or of D-aspartate, a substrate of glutamate transporters that does not activate mGluR. Figure $2 c$ shows that, whereas both compounds lead to comparable $\mathrm{Ca}^{2+}$ increases, only the glutamate transporter substrate D-aspartate caused mitochondrial acidification. Together, these results indicate that glutamate transport mediated the mitochondrial matrix acidification, whereas activation of mGluRs had only a marginal effect on $\mathrm{pH}$.
Glutamate-induced cellular acidification abrogates the cytosol-to-mitochondrial matrix $\mathrm{pH}$ gradient

The $\mathrm{pH}$ gradient and electrical potential across the mitochondrial inner membrane are important determinants for ATP synthesis. Because cytosol and mitochondrial matrix responded to glutamate application with acidifications of different amplitudes (Fig. $1 c$ ), we evaluated the evolution of the $\mathrm{pH}$ gradient across the mitochondrial inner membrane before and during glutamate application.

We performed a statistical analysis of distributions of $\mathrm{pH}$ measured in either the mitochondrial matrix or the cytosol in separate cells and experiments (supplemental Fig. S5, available at www.jneurosci.org as supplemental material). Under basal conditions, the mitochondrial matrix was significantly more alkaline than the cytosol, consistent with the activity of the mitochondrial respiratory chain. However, we found that, during glutamate superfusion, both the mitochondrial matrix and the cytosol reached lower $\mathrm{pH}$ values that were not significantly different (supplemental Fig. S5, available at www.jneurosci.org as supplemental material), suggesting that glutamate uptake abrogates cytosol-to-mitochondrial matrix $\mathrm{pH}$ gradient.

To determine the respective dynamics of mitochondrial matrix and cytosolic $\mathrm{pH}$ during glutamate uptake in the same astrocytes, we loaded MitoSypHer-transfected astrocytes with the cytosolic red dye SNARF-1 (Fig. 3a). The pattern of SNARF-1 fluorescence had typical cytosolic distribution, with nuclei and cytoplasm homogeneously stained. Only astrocytes expressing MitoSypHer exhibited the spectral signature of both fluorophores (Fig. 3b). Consistent with the statistical evaluation described above, the mitochondrial matrix $\mathrm{pH}$ was found to be significantly higher than cytosolic $\mathrm{pH}$ at resting state (Fig. $3 c, d$ ). During glutamate superfusion, the two compartments no longer displayed statistically different $\mathrm{pH}$ values, indicating that glutamate abrogated the $\mathrm{pH}$ gradient between the mitochondrial matrix and the cytosol. Glutamate washout rapidly restored the $\mathrm{pH}$ difference between both compartments. The glutamate transporter substrate D-aspartate $(500 \mu \mathrm{M})$ induced mitochondrial matrix acidification that canceled the transmembrane $\mathrm{pH}$ difference, indicating that glutamate did not induce mitochondrial acidification through intracellular metabolic reactions. The ionotropic glutamate receptor agonist kainate $(500 \mu \mathrm{M})$ induced a mild but significant acidification in both mitochondrial matrix and cytosol, but it was insufficient to cancel the cytosol-tomitochondrial matrix $\mathrm{pH}$ gradient.

\section{Dissociation of cellular $\mathrm{Na}^{+}$and $\mathrm{pH}$ responses to glutamate}

Because astrocytes experience substantial changes of both cytosolic and mitochondrial $\mathrm{Na}^{+}$concentration during glutamate uptake, we investigated the possible inter-dependence of cellular $\mathrm{Na}^{+}$and $\mathrm{pH}$ regulation. We tested a putative role of $\mathrm{Na}^{+} / \mathrm{H}^{+}$exchangers using EIPA $(50 \mu \mathrm{M})$, a compound known to inhibit $\mathrm{Na}^{+} / \mathrm{H}^{+}$exchanger of both plasma membrane and mitochondria, as described in previous studies on the same astrocyte preparation (Bernardinelli et al., 2006). EIPA altered neither resting mitochondrial matrix $\mathrm{pH}$ nor the amplitude of glutamate-induced mitochondrial matrix acidification (supplemental Fig. S6, available at www.jneurosci.org as supplemental material), ruling out a significant contribution of the mitochondrial $\mathrm{Na}^{+} / \mathrm{H}^{+}$exchanger in glutamate-evoked mitochondrial acidification.

We then designed a protocol to dissociate the effects of glutamate on cellular acidification from its effects on sodium concentration, by coadministering the weak base TREA together with glutamate. The concentration of TREA necessary to precisely 
compensate glutamate-induced cytosolic acidification was titrated by superfusing glutamate $(200 \mu \mathrm{M})$ alone, followed by successive applications of TREA at increasing concentrations ( $n=4,32$ cells) (data not shown). In this series of experiments, 6 mM TREA efficiently prevented a $1.5 \mathrm{~min}$ glutamate-induced acidification. Under these conditions, glutamateinduced mitochondrial matrix acidification was severely impaired. In contrast, both cytosolic and mitochondrial $\mathrm{Na}^{+}$responses to glutamate, measured with SBFI-AM and the mitochondrial $\mathrm{Na}^{+}$indicator CoroNa Red, respectively, were essentially maintained, indicating that TREA did not prevent $\mathrm{Na}^{+}$-coupled glutamate transport (Fig. 4a). Together, these experiments suggest that glutamateinduced cellular acidification and $\mathrm{Na}^{+}$responses are not strictly coupled. In addition, this protocol enabled producing a chemical ablation of glutamate-induced cellular acidification that has subsequently been used to highlight the role of $\mathrm{pH}$ on glutamate-induced metabolic changes. As seen in Figure $4 b$, the alkalinizing effect of TREA somewhat declined during its application. Therefore, the concentration of TREA was adapted for each subsequent series of experiments and protocols.

\section{Glutamate induces a pH-mediated} decrease in oxygen consumption rate and mitochondrial reactive oxygen species production We then investigated whether glutamate-induced mitochondrial acidification has an impact on mitochondrial physiology. In these experiments, astrocytes were preincubated in the presence of the glycolysis inhibitor 2-deoxyglucose (2-DG) and pyruvate was added as a mitochondrial energy substrate to promote mitochondrial ATP production and avoid potential confounding effects of glycolysis activation. In this condition, the oxygen consumption rate was approximately equal to that measured at the end of experiments in the presence of the mitochondrial uncoupler FCCP (Fig. 5a), suggesting that mitochondrial respiration was close to its maximal capacity. mROS production rate (see below) was also approximately threefold greater in glycolysis-inhibited astrocytes compared with a glucose-containing medium $(p<$ 0.001; $n=42,250$ cells).

Using a fluorescence-based oxygen analyzer, we measured the oxygen consumption rate in the vicinity of intact astrocytes during glutamate uptake. We found that glutamate decreased the oxygen consumption rate to $88 \pm 1 \%$ of the basal level (Fig. 5). However, when glutamate was applied together with TREA to prevent intracellular acidification, the oxygen consumption rate remained unchanged. It is important to mention that the glutamate-mediated decrease of respiration was also observed when with glycolysis was functional, i.e., in glucose medium without 2-DG. Under these conditions, glutamate decreased oxygen consumption rate by $17 \pm 3 \%(n=20)$.

To investigate whether glutamate-mediated decrease of oxygen consumption could be explained by modulation of nonrespi- ratory processes, we first inhibited coupled respiration using oligomycin ( $\mathrm{F}_{0} \mathrm{~F}_{1}$ ATPase inhibitor) and measured the remaining oxygen consumption. This residual oxygen consumption is attributable to uncoupled respiration (i.e., proton leak) and other oxidative processes. Supplemental Figure S7 (available at www. jneurosci.org as supplemental material) indicates that, when glutamate was subsequently added on top of oligomycin, no additional reduction in oxygen consumption rate was observed. This result indicates that the glutamate-mediated decline of oxygen consumption can be entirely attributed to the coupled respiration and that other oxygen-consuming processes did not contribute to the observed decrease. Together, these experiments suggest that glutamate induces a $\mathrm{pH}$-mediated decrease of mitochondrial oxygen respiration in astrocytes.

During normal mitochondrial respiration, $0.2-2 \%$ of consumed oxygen is transformed into mROS from complexes I and III of the mitochondrial respiratory chain (Balaban et al., 2005). We reasoned that, if glutamate induced a decrease in mitochondrial respiration, it should also decrease mROS production rate. To investigate this hypothesis, we used the mROS-sensitive probe MitoSOX Red, which selectively loads into mitochondria (supplemental Fig. S8, available at www.jneurosci.org as supplemental material) and becomes fluorescent when oxidized by mROS. Measuring the slope of MitoSOX Red fluorescence increase enabled real-time monitoring alterations of the mROS production rate. During application of glutamate, mROS production was altered in a biphasic way (Fig. $6 a$ ) in which an initial increase of mROS production rate was followed by a sustained decrease to 

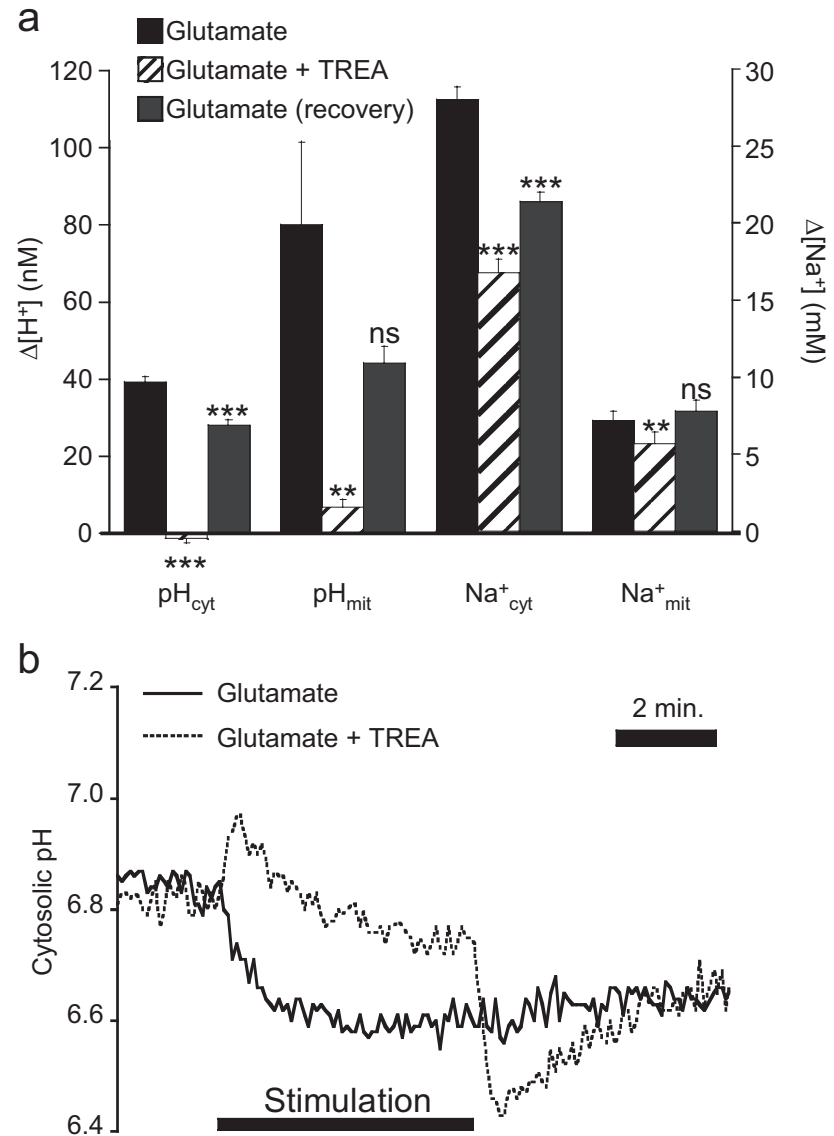

Figure 4. Independence of cellular $\mathrm{Na}^{+}$and pH responses to glutamate. $\boldsymbol{a}$, Glutamateevoked cellular $\mathrm{Na}^{+}$responses without concomitant pH changes. After a first control pulse of glutamate application, glutamate was superfused together with $6 \mathrm{~mm}$ TREA, the concentration found to compensate glutamate-induced cytosolic acidification. $\mathrm{pH}$ measurements in the cytosol $\left(\mathrm{pH}_{\text {cyt }} ; n=4,32\right.$ cells) and mitochondrial matrix ( $\mathrm{pH}_{\text {mit; }} ; n=6,20$ cells) and $\mathrm{Na}^{+}$measurements in the cytosol ( $\mathrm{Na}^{+}{ }_{\text {cyt }} ; n=4,30$ cells) and mitochondria ( $\mathrm{Na}^{+}{ }_{\text {mit }} ; n=4,32$ cells) were taken after $1.5 \mathrm{~min}$ of stimulation. Data are presented as means \pm SEM. $\boldsymbol{b}$, Cytosolic pH measurement during a pulse of $200 \mu \mathrm{m}$ glutamate (solid line) and during glutamate plus TREA application (dotted line). In the example shown, $10.7 \mathrm{~mm}$ TREA effectively prevented the acidification during glutamate application, as measured after $5 \mathrm{~min}$ of glutamate application.

$75 \pm 3 \%$ of the initial value within $1.5 \mathrm{~min}$. mROS production rate did not immediately recover to baseline after glutamate washout. The transient increase in mROS production rate was abolished in the presence of the cell-permeable superoxide dismutase mimetic MnTMPyP (Strathmann et al., 2010), applied on cells $10 \mathrm{~min}$ before glutamate stimulation. Conversely, the subsequent sustained decrease in mROS induced by glutamate was somewhat enhanced in the presence of ROS scavenger. The first transient increase in mROS was prevented when mGluRs were inhibited using (+)- $\alpha$-methyl-4-carboxyphenylglycine (MCPG) (1 mM) but did not prevent the following steady decrease. Blocking glutamate uptake using TBOA during glutamate application led to a stable increase of mROS production rate as measured after 5 min of stimulation (Fig. $6 b$ ). The inhibition of glutamate uptake may have actually unveiled the stimulatory effect mediated by metabotropic glutamate receptors on mROS production rate occurring in the absence of intracellular acidification, which involves $\mathrm{Ca}^{2+}$ responses (Fig. 2c). To test this hypothesis, we stimulated astrocytes with glutamate in the presence of TBOA and the metabotropic glutamate receptor inhibitor MCPG. MCPG prevented the steady increase of mROS production rate in

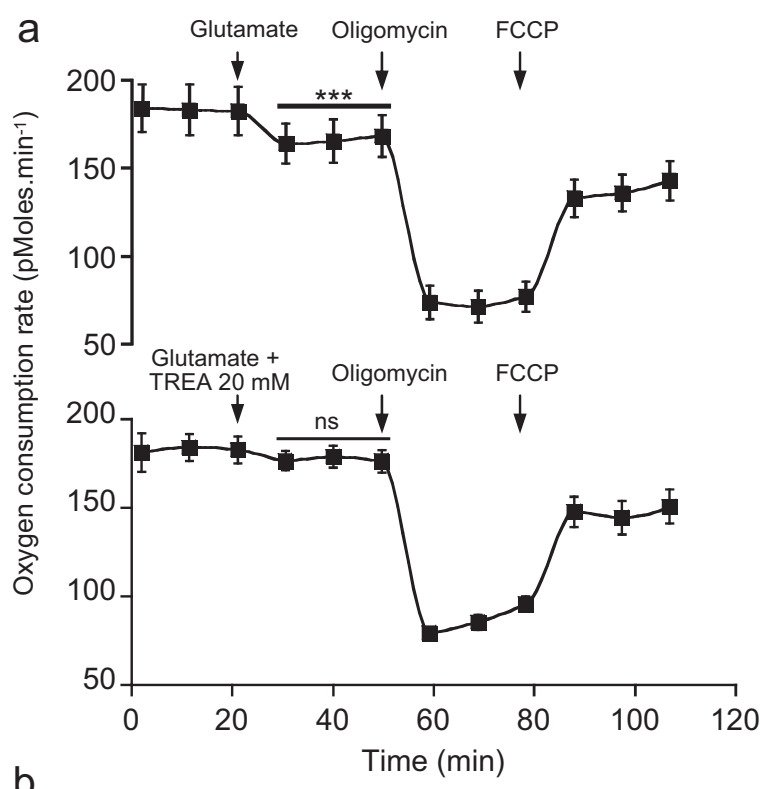

b

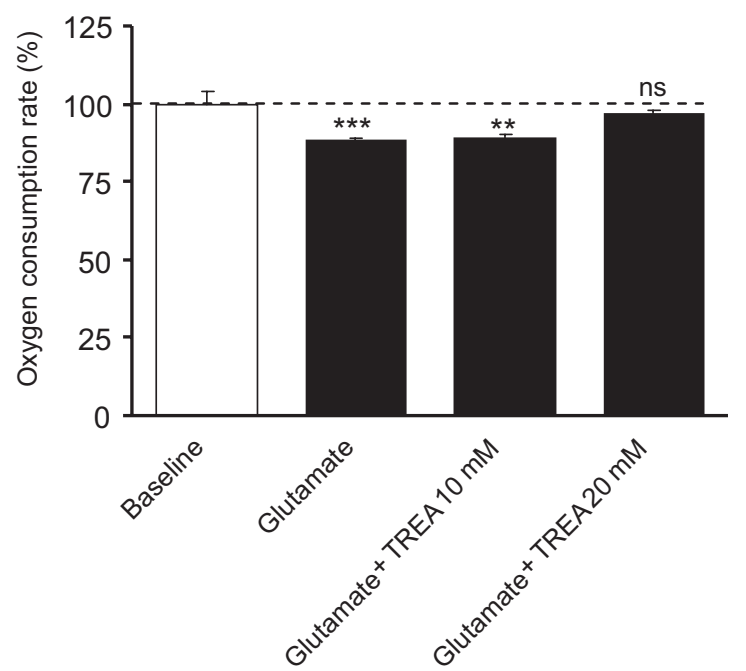

Figure 5. Glutamate induces a pH-mediated decrease of oxygen consumption rate. Glycolysis was inhibited using 2-DG (10 mM) to promote mitochondrial activity, and glucose $(5 \mathrm{~mm})$ and pyruvate $(5 \mathrm{~mm})$ were given as substrates. $\boldsymbol{a}$, Time course of oxygen consumption rate in intact astrocytes in the absence and presence of glutamate (top; $n=$ 7). When glutamate-induced cellular acidification was compensated by coadministration of TREA $(20 \mathrm{~mm})$, glutamate no longer significantly decreased oxygen consumption rate (bottom; $n=6$ ). As a control, mitochondrial respiration was inhibited using oligomycin (5 $\mu \mathrm{m})$ and then increased using FCCP $(2 \mu \mathrm{M})$ at the end of each experiment. $\boldsymbol{b}$, Average data of glutamate-induced decrease in oxygen consumption rate with increasing concentrations of TREA. Data were normalized to oxygen consumption rate before glutamate addition for each experiment $(n=42)$.

the presence of glutamate and TBOA (Fig. 6b). We then tested whether the steady decrease in mROS production rate caused by glutamate was linked to glutamate-evoked intracellular acidification. When glutamate-induced acidification was compensated using TREA, glutamate no longer altered mitochondrial ROS production rate. Together, these experiments suggest that glutamate induces a $\mathrm{pH}$-mediated alteration of mROS production rate characterized by an initial transient increase of mROS production rate mediated by mGluRs followed by a stable decrease of mROS production rate attributable to intracellular acidification. 

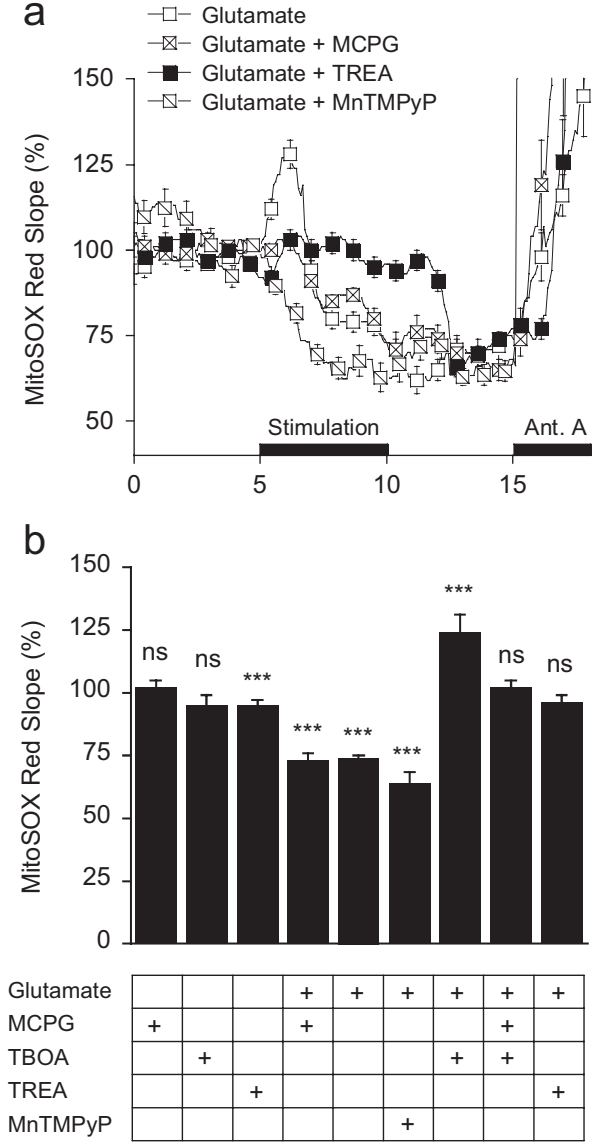

Figure 6. Glutamate induced a pH-mediated alteration of mROS production rate. Glycolysis was inhibited using 2-DG (10 mM) to promote mitochondrial activity, and pyruvate $(5 \mathrm{~mm})$ was given as mitochondrial substrate. The mROS production rate during 2-DG plus pyruvate phase was considered as the reference rate of $100 \%$. $\boldsymbol{a}$, Time course of mROS production rate during stimulation with glutamate, coadministration of glutamate and TREA (10.7 mM), glutamate and MCPG (1 mM), or glutamate in the presence of the ROS scavenger MnTMPyP $(50 \mu \mathrm{M})$. At the end of each experiment, antimycin A (Ant. A) was used as a positive control of mROS detection. Traces are shown as mean signals with error bars (SEM) displayed every 10th time point for graphical clarity. $\boldsymbol{b}$, Mean values of mROS production rate after 5 min of stimulation. Conditions: MCPG ( $n=5,30$ cells); TBOA ( $n=3,12$ cells); TREA ( $n=6,34$ cells); glutamate $(n=6,34$ cells); glutamate $+\operatorname{MCPG}(n=5,30$ cells); glutamate $+\operatorname{MnTMPyP}(n=3,26$ cells); glutamate + TBOA $(n=6,36$ cells); glutamate + TBOA + MCPG $(n=6,45$ cells); glutamate + TREA ( $n=6,30$ cells). Statistical analysis was done for each group by comparison with the MitoSOX slope before stimulation. All data shown are means \pm SEM.

\section{Neuronal release of glutamate triggers mitochondrial matrix acidification in astrocytes}

Finally, we asked whether glutamate released by neurons during activity could cause mitochondrial matrix acidification in astrocytes. To address this issue, we set up a mixed culture model resembling the in vivo cytoarchitecture, in which astrocyte membranes are in close proximity with neuronal synapses. Cortical astrocytes previously transfected with MitoSypHer were cocultured with neurons for 2 weeks. Under differential interference contrast (DIC) microscopy, neurons were recognizable by their pyramidal soma with several extending processes (Fig. $7 a$ ). Astrocytes expressing MitoSypHer were identified by their mitochondrial fluorescent pattern. In this preparation, synaptic boutons were in close apposition with astrocyte mitochondria labeled with MitoSypHer (supplemental Fig. S9a, available at www.jneurosci.org as supplemental material). In addition, we determined that a 20 s application of NMDA $(10 \mu \mathrm{M})$ reliably and
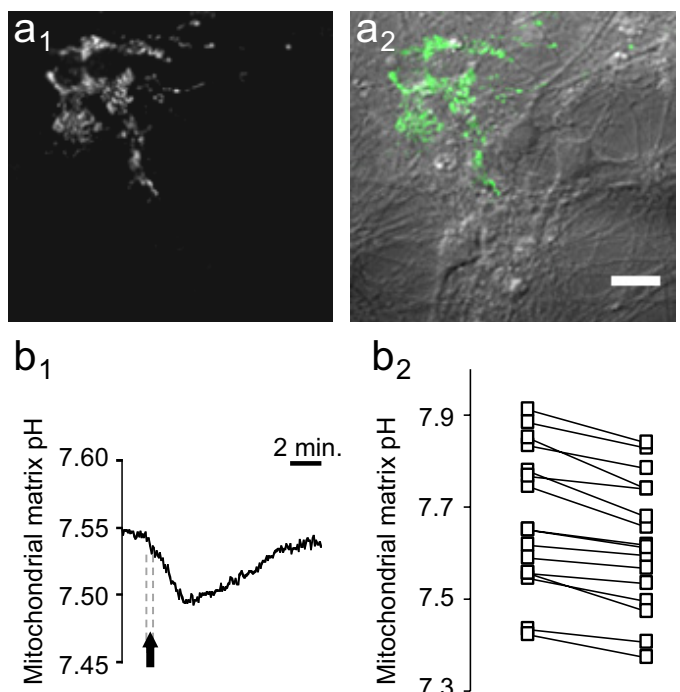

$\mathrm{b}_{2}$
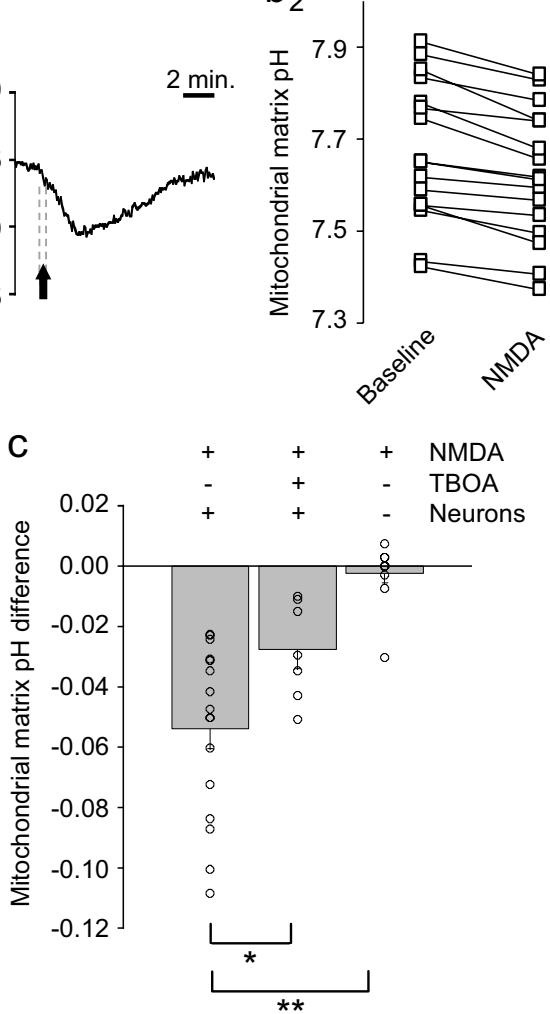

Figure 7. Neuronal release of glutamate triggers glutamate transporter-mediated mitochondrial matrix acidification in astrocytes. Images depicting fluorescent MitoSypHer expression in astrocytes $\left(\boldsymbol{a}_{7}\right)$ surrounding neurons visible under DIC $\left(\boldsymbol{a}_{2}\right)$. Scale bar, $20 \mu \mathrm{m} . \boldsymbol{b}_{1}$, MitoSypHer fluorescence excitation ratio monitored in astrocytes during a $20 \mathrm{~s}$ stimulation of neurons using NMDA $(10 \mu \mathrm{M})$. Representative trace $\left(\boldsymbol{b}_{1}\right)$ and individual data $\left(\boldsymbol{b}_{2}\right)$ of mitochondrial matrix $\mathrm{pH}$ of astrocytes at baseline and after NMDA stimulation. $c$, Amplitudes of NMDAevoked astrocyte mitochondrial matrix acidification in the absence or presence of TBOA and neurons. NMDA ( $n=9,16$ cells); NMDA + TBOA $(n=5,7$ cells); $\operatorname{NMDA}$ without neurons $(n=$ 4,11 cells). ${ }^{*} p<0.05$ and ${ }^{* *} p<0.01$ using unpaired Student's $t$ test.

selectively evoked a reversible cytosolic $\mathrm{Ca}^{2+}$ increase in neurons, even in the presence of TBOA. Consistent with previous reports (Verkhratsky and Steinhauser, 2000), we found that NMDA had no effect on cytosolic $\mathrm{Ca}^{2+}$ levels in pure culture of astrocytes (supplemental Fig. S $9 b, c$, available at www.jneurosci.org as supplemental material). Therefore, NMDA application was used as a tool to evoke neuronal excitatory responses expected to stimulate glutamate release, and mitochondrial matrix $\mathrm{pH}$ was measured in surrounding MitoSypHer-transfected astrocytes.

Figure $7 b$ shows that, during a $20 \mathrm{~s}$ NMDA stimulation, the mitochondrial matrix $\mathrm{pH}$ of astrocytes declined to a maximal acidification of $0.05 \pm 0.01 \mathrm{pH}$ units after $112 \pm 15 \mathrm{~s}$. Mitochondrial matrix $\mathrm{pH}$ recovered to its initial value $4-5 \mathrm{~min}$ later. In the absence of neurons, NMDA application did not significantly alter the mitochondrial matrix $\mathrm{pH}$ (Fig. $7 c$ ), indicating that NMDA- 
triggered mitochondrial matrix acidification in astrocytes is specifically linked to neuronal activity. We used TBOA to investigate whether in this situation astrocyte mitochondrial matrix acidification is mediated by plasma membrane uptake of glutamate. TBOA alone did not significantly alter the basal mitochondrial matrix $\mathrm{pH}(0.03 \pm 0.02 ; n=5,7$ cells; $p>0.05)$. Consistent with results presented above (Fig. 2) (supplemental Fig. S3, available at www.jneurosci.org as supplemental material), TBOA diminished the astrocyte mitochondrial matrix acidification in response to NMDA-mediated neuronal activation (Fig. 7c). The extent of inhibition was however not as pronounced as in pure astrocyte cultures. Together, these experiments suggest that the glutamate released by neurons during synaptic activity induces a glutamate transporter-mediated mitochondrial matrix acidification in astrocytes.

\section{Discussion}

This study was designed to evaluate the impact of glutamatergic neurotransmission on mitochondrial metabolism of astrocytes. We show that glutamate uptake in astrocytes causes a $\mathrm{pH}$ modulation in mitochondria that rapidly impacts on the oxidative metabolism.

Glutamate uptake through high-affinity $\mathrm{Na}^{+}$-coupled transporters has been identified as the first step that enables astrocytes to sense the level of excitatory neuronal activity and to provide a proportionate metabolic response (Pellerin and Magistretti, 1994; Magistretti et al., 1999; Voutsinos-Porche et al., 2003). The influx of $\mathrm{Na}^{+}$ions and subsequent activation of the $\mathrm{Na}, \mathrm{K}$ ATPase have been shown to enhance glucose capture from the extracellular space. It has been estimated that glutamate transporter-mediated $\mathrm{Na}^{+}$influx increased the overall ATP consumption by approximately twofold to threefold (Chatton et al., 2000). Glutamate transporters have a complex stoichiometry of one glutamate cotransported with three $\mathrm{Na}^{+}$and one proton in exchange with one $\mathrm{K}^{+}$(Levy et al., 1998). Thus, transporter activity includes an inward movement of one proton with each cycle of transport, explaining the observed cellular acidification. Astrocytes, both in primary culture and in vivo, possess a substantial density of mitochondria, the site of oxidative phosphorylation and energy powerhouse of cells. During glutamatergic stimulation, the increased mitochondrial concentrations of $\mathrm{Ca}^{2+}$ and $\mathrm{Na}^{+}$would be expected to stimulate mitochondrial respiration through activation of $\mathrm{Ca}^{2+}$-dependent dehydrogenases (Hajnóczky et al., 1995) and through increased pyruvate dehydrogenase activity (Pawelczyk and Olson, 1995), respectively. Glutamate taken up in astrocytes could also represent a substrate of the Krebs' cycle after conversion to $\alpha$-ketoglutarate by the mitochondrial matrix enzyme glutamate dehydrogenase (Hertz et al., 2007).

The present study has investigated the impact of $\mathrm{pH}$ changes on astrocytic mitochondrial metabolism. In acute slices, neuronal activity was shown to induce cytosolic alkaline transients in the soma of astrocytes that follows extracellular potassium concentration increases (Chesler and Kraig, 1989). In contrast, the plasma membrane $\mathrm{Na}^{+}$-glutamate cotransporters coupled to proton entry causes cytosolic acidification (Amato et al., 1994; Rose and Ransom, 1996). It has recently been reported that, in situ, hippocampal neuronal stimulation is followed by glutamate uptake in astrocytes coincident with increases of cytosolic $\mathrm{Na}^{+}$ concentration in their fine processes (Langer and Rose, 2009). Similarly, glutamate transporter activity could potentially create local acidic cytoplasmic microdomains at the interface of plasma and mitochondrial membranes that could promote proton trans- location into mitochondria. Because the ionic composition of the mitochondrial intermembrane space is considered to be equivalent to that of the cytosol, cytosolic $\mathrm{pH}$ changes are expected to alter $\mathrm{pH}$ gradient across mitochondrial inner membrane. We therefore engaged in investigations of mitochondrial $\mathrm{pH}$ in intact astrocytes using MitoSypHer, a novel genetically encoded $\mathrm{pH}$ sensor targeted to the mitochondrial matrix (Poburko et al., 2011).

We discovered that mitochondria of astrocytes undergo substantial acidification during glutamate uptake. By using an experimental model of cocultures of neurons and astrocytes, which enabled selective monitoring of mitochondrial $\mathrm{pH}$ in astrocytes, we discovered that evoking neuronal activity caused a sustained acidification in astrocyte mitochondria. The experimental evidence collected in this study indicates that the mechanism of acidification involves plasma membrane glutamate transporters for several reasons: (1) kinetic parameters of glutamate-evoked mitochondrial matrix acidifications closely matched values found for plasma membrane glutamate transporters (Chatton et al., 2000); (2) TBOA strongly inhibited the glutamate-evoked mitochondrial matrix acidification; (3) the alternate transporter substrate D-aspartate led to similar acidifications; (4) glutamate did not induce mitochondrial acidification in cultured HEK-293 cells that do not express glutamate transporters; and (5) a cytosolic $\mathrm{Ca}^{2+}$ increase evoked by the mGluRs agonist $t$-ACPD caused only a mild - if any — change of mitochondrial matrix $\mathrm{pH}$ in contrast to what was observed in HeLa cells (Poburko et al., 2011). Altogether, these data excluded the involvement of mGluRs in the glutamate-evoked mitochondrial matrix acidification and are consistent with glutamate transporters including an inward movement of a proton with each cycle of transport, thereby acidifying cells.

Data presented here did not point toward $\mathrm{Na}^{+}$and mitochondrial $\mathrm{Na}^{+} / \mathrm{H}^{+}$exchangers as main contributors to the observed mitochondrial $\mathrm{pH}$ response, because EIPA was without effect. The fact that kainate, which causes a cytosolic $\mathrm{Na}^{+}$rise of similar amplitude as glutamate in astrocytes (Chatton et al., 2000), barely acidified mitochondria is another element against $\mathrm{Na}^{+} / \mathrm{H} \mathrm{ex}-$ changer contribution. Compensating cellular $\mathrm{pH}$ changes during glutamate uptake by administration of weak base, effectively abrogated the mitochondrial $\mathrm{pH}$ drop but maintained most of the $\mathrm{Na}^{+}$response. Also, application of kainate, which causes a substantial $\mathrm{Na}^{+}$elevation (Chatton et al., 2000; Bernardinelli et al., 2006), caused only a minor mitochondrial acidification. The fact that the acidification caused by kainate did not cancel the $\mathrm{pH}$ gradient likely comes from the fact that kainate generated less cytosolic acidification that was entirely handled by mitochondrial regulatory mechanisms. Under the current experimental conditions, it appears that protons are translocated across the mitochondrial membranes by other transport mechanisms. It is currently known that mitochondria do possess channels for cations, as well as numerous exchangers and cotransporters involving transmembrane cation movements, and that energy dissipation is limited by the fact that they are tightly regulated (Bernardi, 1999). For instance, we and others have demonstrated that cytosolic $\mathrm{Na}^{+}$enters mitochondria, in which its concentration is regulated (Bernardinelli et al., 2006). Several candidate pathways exist for proton entry, including uncoupling proteins (proton leak), and cation-proton exchangers. Besides ion transport, shuttling of metabolites or of organic weak acids or bases might also move protons across the inner mitochondrial membrane. However, the fact that glutamate does not depolarize but rather mildly hyperpolarize mitochondria in astrocytes (Kahlert 
et al., 2008) does not support a cationic (proton) channel opening.

Several experimental data point to the fact that $\mathrm{pH}$ profoundly influences cellular functions, for instance, by direct $\mathrm{pH}$ modulation of enzymes (Casey et al., 2010). At the mitochondria level, besides enzymatic $\mathrm{pH}$ modulation, the proton gradient across the mitochondrial membrane is central to the ability of mitochondria to synthesize ATP. Such regulation has been observed recently in pancreatic $\beta$-cells (Wiederkehr et al., 2009), in which mitochondrial matrix $\mathrm{pH}$ was found to be a key determinant of mitochondrial energy metabolism. We simultaneously evaluated the dynamics of cytosolic and mitochondrial matrix $\mathrm{pH}$ and found that the $\mathrm{pH}$ gradient across mitochondrial inner membrane was abrogated during glutamate uptake. Therefore, we examined whether the observed acidification in mitochondria directly influenced their metabolic function. Direct monitoring of the oxygen consumption of astrocytes during glutamate uptake demonstrated that a significant decrease of respiration was taking place during glutamate uptake that depended on intracellular acidification. The glutamate-induced decrease of mitochondrial respiration was then confirmed by measuring the production of mROS, a side product of electron transport in the respiratory chain (Balaban et al., 2005). We found that glutamate application steadily decreased mROS output of astrocytes, an observation compatible with the notion that glutamate entry reduces the mitochondrial respiratory chain electron flow. Interestingly, as was found for oxygen consumption, glutamate uptake without concomitant intracellular acidification did not alter mROS production rate, highlighting the central role of acidification in the glutamate effects. This observation is in line with results presented with isolated mitochondria (Selivanov et al., 2008 ) in which mROS production was strongly impaired by lowering mitochondrial matrix $\mathrm{pH}$. This was found to be the case when matrix and extramitochondrial milieus both shifted to acidic or alkaline values (transmembrane $\mathrm{pH}$ gradient kept intact) and also when both milieus were clamped to the same acidic $\mathrm{pH}$ (zero $\mathrm{pH}$ gradient). In the context of the present study, it means that acidification of the matrix by glutamate even when the delta $\mathrm{pH}$ is not collapsed has important functional consequences for mitochondrial functional output of astrocytes.

It is worth noting that the opposite situation may occur in neurons because neuronal metabolism is preferentially oxidative (Tsacopoulos and Magistretti, 1996; Herrero-Mendez et al., 2009) and mainly regulated by a Ca ${ }^{2+}$-dependent signaling during activity (Duchen, 1992). Indeed, glutamate was found to induce a mitochondrial matrix alkalinization in neurons (Abad et al., 2004), a situation associated with increase in mitochondrial ATP production (Wiederkehr et al., 2009). Our results also suggested that mGluRs activation by glutamate enhances mitochondrial metabolism in astrocytes in situations in which glutamate uptake is not taking place. These results raise the possibility of a differential regulation of mitochondrial metabolism within cellular compartments of the astrocytes. In fine processes in which the cytosolic calcium increase dominates, mitochondrial metabolism may increase, whereas mitochondria close to glutamate transporters in perisynaptic processes are most likely to be affected by the glutamate-induced decrease in intracellular $\mathrm{pH}$.

Glutamate capture associated with excitatory neurotransmission has a high energy cost. Without the ability to increase their mitochondrial metabolism, astrocytes appear to resort to aerobic glycolysis as an alternative way to meet increased energy demands. Our measurements of functional mitochondrial output provide a plausible explanation for the described prevalence of the glycolytic response (Pellerin and Magistretti, 1994) as a means of providing sufficient ATP during glutamate uptake. We propose therefore that glutamate transport tunes oxidative metabolism in perisynaptic domains during $\mathrm{Na}^{+}$-mediated increase in ATP demands by a pH-mediated decrease in mitochondrial metabolism. The coincidence of the two phenomena promotes the glycolytic metabolism of glucose and the release of glycolysisderived lactate, as an energy substrate for activated neurons. In addition, by limiting mitochondrial respiration in astrocytes, uptake of glutamate may prevent excessive astrocytic mROS production while maximizing oxygen availability for instance for neurons.

\section{References}

Abad MF, Di Benedetto G, Magalhães PJ, Filippin L, Pozzan T (2004) Mitochondrial $\mathrm{pH}$ monitored by a new engineered green fluorescent protein mutant. J Biol Chem 279:11521-11529.

Alle H, Roth A, Geiger JR (2009) Energy-efficient action potentials in hippocampal mossy fibers. Science 325:1405-1408.

Amato A, Ballerini L, Attwell D (1994) Intracellular pH changes produced by glutamate uptake in rat hippocampal slices. J Neurophysiol 72:1686-1696.

Balaban RS, Nemoto S, Finkel T (2005) Mitochondria, oxidants, and aging. Cell 120:483-495.

Bernardi P (1999) Mitochondrial transport of cations: channels, exchangers, and permeability transition. Physiol Rev 79:1127-1155.

Bernardinelli Y, Azarias G, Chatton JY (2006) In situ fluorescence imaging of glutamate-evoked mitochondrial $\mathrm{Na}^{+}$responses in astrocytes. Glia 54:460-470.

Bezzi P, Gundersen V, Galbete JL, Seifert G, Steinhäuser C, Pilati E, Volterra A (2004) Astrocytes contain a vesicular compartment that is competent for regulated exocytosis of glutamate. Nat Neurosci 7:613-620.

Blachly-Dyson E, Forte M (2001) VDAC channels. IUBMB Life 52:113-118

Casey JR, Grinstein S, Orlowski J (2010) Sensors and regulators of intracellular pH. Nat Rev Mol Cell Biol 11:50-61.

Chatton JY, Marquet P, Magistretti PJ (2000) A quantitative analysis of L-glutamate-regulated $\mathrm{Na}^{+}$dynamics in mouse cortical astrocytes: implications for cellular bioenergetics. Eur J Neurosci 12:3843-3853.

Chatton JY, Idle JR, Vågbø CB, Magistretti PJ (2001) Insights into the mechanisms of ifosfamide encephalopathy: drug metabolites have agonistic effects on alpha-amino-3-hydroxy-5-methyl-4-isoxazolepropionic acid (AMPA)/kainate receptors and induce cellular acidification in mouse cortical neurons. J Pharmacol Exp Ther 299:1161-1168.

Chatton JY, Pellerin L, Magistretti PJ (2003) GABA uptake into astrocytes is not associated with significant metabolic cost: implications for brain imaging of inhibitory transmission. Proc Natl Acad Sci USA 100:12456-12461.

Chaudhry FA, Lehre KP, van Lookeren Campagne M, Ottersen OP, Danbolt NC, Storm-Mathisen J (1995) Glutamate transporters in glial plasma membranes: highly differentiated localizations revealed by quantitative ultrastructural immunocytochemistry. Neuron 15:711-720.

Chesler M, Kraig RP (1989) Intracellular $\mathrm{pH}$ transients of mammalian astrocytes. J Neurosci 9:2011-2019.

Duchen MR (1992) $\mathrm{Ca}^{2+}$-dependent changes in the mitochondrial energetics in single dissociated mouse sensory neurons. Biochem J 283:41-50.

Grosche J, Matyash V, Möller T, Verkhratsky A, Reichenbach A, Kettenmann H (1999) Microdomains for neuron-glia interaction: parallel fiber signaling to Bergmann glial cells. Nat Neurosci 2:139-143.

Hajnóczky G, Robb-Gaspers LD, Seitz MB, Thomas AP (1995) Decoding of cytosolic calcium oscillations in the mitochondria. Cell 82:415-424.

Haugeto O, Ullensvang K, Levy LM, Chaudhry FA, Honoré T, Nielsen M, Lehre KP, Danbolt NC (1996) Brain glutamate transporter proteins form homomultimers. J Biol Chem 271:27715-27722.

Herrero-Mendez A, Almeida A, Fernández E, Maestre C, Moncada S, Bolaños JP (2009) The bioenergetic and antioxidant status of neurons is controlled by continuous degradation of a key glycolytic enzyme by APC/CCdh1. Nat Cell Biol 11:747-752.

Hertz L, Peng L, Dienel GA (2007) Energy metabolism in astrocytes: high rate of oxidative metabolism and spatiotemporal dependence on glycolysis/glycogenolysis. J Cereb Blood Flow Metab 27:219-249.

Kahlert S, Zündorf G, Reiser G (2008) Detection of de- and hyperpolariza- 
tion of mitochondria of cultured astrocytes and neurons by the cationic fluorescent dye rhodamine 123. J Neurosci Methods 171:87-92.

Langer J, Rose CR (2009) Synaptically induced sodium signals in hippocampal astrocytes in situ. J Physiol 587:5859-5877.

Levy LM, Warr O, Attwell D (1998) Stoichiometry of the glial glutamate transporter GLT-1 expressed inducibly in a Chinese hamster ovary cell line selected for low endogenous $\mathrm{Na}^{+}$-dependent glutamate uptake. J Neurosci 18:9620-9628.

Lovatt D, Sonnewald U, Waagepetersen HS, Schousboe A, He W, Lin JH, Han X, Takano T, Wang S, Sim FJ, Goldman SA, Nedergaard M (2007) The transcriptome and metabolic gene signature of protoplasmic astrocytes in the adult murine cortex. J Neurosci 27:12255-12266.

Magistretti PJ (2009) Neuroscience. Low-cost travel in neurons. Science 325:1349-1351.

Magistretti PJ, Pellerin L, Rothman DL, Shulman RG (1999) Energy on demand. Science 283:496-497.

Mitchell P (1979) Keilin's respiratory chain concept and its chemiosmotic consequences. Science 206:1148-1159.

Oberheim NA, Takano T, Han X, He W, Lin JH, Wang F, Xu Q, Wyatt JD, Pilcher W, Ojemann JG, Ransom BR, Goldman SA, Nedergaard M (2009) Uniquely hominid features of adult human astrocytes. J Neurosci 29:3276-3287.

Pawelczyk T, Olson MS (1995) Changes in the structure of pyruvate dehydrogenase complex induced by mono- and divalent ions. Int J Biochem Cell Biol 27:513-521.

Pellerin L, Magistretti PJ (1994) Glutamate uptake into astrocytes stimulates aerobic glycolysis: a mechanism coupling neuronal activity to glucose utilization. Proc Natl Acad Sci U S A 91:10625-10629.

Pellerin L, Magistretti PJ (2003) Food for thought: challenging the dogmas. J Cereb Blood Flow Metab 23:1282-1286.

Poburko D, Santo-Domingo J, Demaurex N (2011) Dynamic regulation of the mitochondrial proton gradient during cytosolic calcium elevation. J Biol Chem. Advance online publication. Retrieved Feb 14, 2011. doi: 10.1074/jbc.M110.159962.

Porcelli AM, Ghelli A, Zanna C, Pinton P, Rizzuto R, Rugolo M (2005) pH difference across the outer mitochondrial membrane measured with a green fluorescent protein mutant. Biochem Biophys Res Commun 326:799-804.

Robinson KM, Janes MS, Pehar M, Monette JS, Ross MF, Hagen TM, Murphy MP, Beckman JS (2006) Selective fluorescent imaging of superoxide in vivo using ethidium-based probes. Proc Natl Acad Sci U S A 103: $15038-15043$.
Rose CR, Ransom BR (1996) Mechanisms of $\mathrm{H}^{+}$and $\mathrm{Na}^{+}$changes induced by glutamate, kainate, and $\mathrm{D}$-aspartate in rat hippocampal astrocytes. J Neurosci 16:5393-5404

Rouach N, Koulakoff A, Abudara V, Willecke K, Giaume C (2008) Astroglial metabolic networks sustain hippocampal synaptic transmission. Science 322:1551-1555.

Schummers J, Yu H, Sur M (2008) Tuned responses of astrocytes and their influence on hemodynamic signals in the visual cortex. Science 320:1638-1643.

Selivanov VA, Zeak JA, Roca J, Cascante M, Trucco M, Votyakova TV (2008) The role of external and matrix $\mathrm{pH}$ in mitochondrial reactive oxygen species generation. J Biol Chem 283:29292-29300.

Serres S, Raffard G, Franconi JM, Merle M (2008) Close coupling between astrocytic and neuronal metabolisms to fulfill anaplerotic and energy needs in the rat brain. J Cereb Blood Flow Metab 28:712-724.

Sibson NR, Dhankhar A, Mason GF, Rothman DL, Behar KL, Shulman RG (1998) Stoichiometric coupling of brain glucose metabolism and glutamatergic neuronal activity. Proc Natl Acad Sci U S A 95:316-321.

Sorg O, Magistretti PJ (1992) Vasoactive intestinal peptide and noradrenaline exert long-term control on glycogen levels in astrocytes: blockade by protein synthesis inhibition. J Neurosci 12:4923-4931.

Strathmann J, Klimo K, Sauer SW, Okun JG, Prehn JH, Gerhäuser C (2010) Xanthohumol-induced transient superoxide anion radical formation triggers cancer cells into apoptosis via a mitochondria-mediated mechanism. FASEB J 24:2938-2950.

Tsacopoulos M, Magistretti PJ (1996) Metabolic coupling between glia and neurons. J Neurosci 16:877-885.

Verkhratsky A, Steinhäuser C (2000) Ion channels in glial cells. Brain Res Brain Res Rev 32:380-412.

Voutsinos-Porche B, Bonvento G, Tanaka K, Steiner P, Welker E, Chatton JY, Magistretti PJ, Pellerin L (2003) Glial glutamate transporters mediate a functional metabolic crosstalk between neurons and astrocytes in the mouse developing cortex. Neuron 37:275-286.

Wiederkehr A, Park KS, Dupont O, Demaurex N, Pozzan T, Cline GW, Wollheim CB (2009) Matrix alkalinization: a novel mitochondrial signal for sustained pancreatic beta-cell activation. EMBO J 28:417-428.

Wyss MT, Weber B, Treyer V, Heer S, Pellerin L, Magistretti PJ, Buck A (2009) Stimulation-induced increases of astrocytic oxidative metabolism in rats and humans investigated with 1-11C-acetate. J Cereb Blood Flow Metab 29:44-56. 